\title{
Permeability of $\mathrm{MgCl}_{2}$ - Graphite Reactive Compound
}

ISSN: 2576-8840

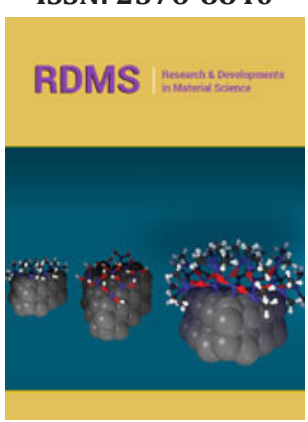

*Corresponding author: Kent S Udell, Department of Mechanical Engineering, University of Utah, USA

Submission: 战 November 23, 2020

Published: 漈December 14, 2020

Volume 14 - Issue 4

How to cite this article: Seyyed Ali Hedayat Mofidi and Kent S Udell. Permeability of $\mathrm{MgCl}_{2}$ - Graphite Reactive Compound. Res DevMaterialSci.14(4).RDMS.000842.2020. DOI: 10.31031/RDMS.2020.14.000842

Copyright@ Kent S Udell. This article is distributed under the terms of the Creative Commons Attribution 4.0 International License, which permits unrestricted use and redistribution provided that the original author and source are credited.

\author{
Seyyed Ali Hedayat Mofidi and Kent S Udell*
}

Department of Mechanical Engineering, University of Utah, USA

\begin{abstract}
Mass transfer limitations due to decreasing permeabilities of the absorbing matrix has been observed to decrease the performance of thermochemical energy storage systems. In this study, the permeability of a reactive complex consisting ammoniated magnesium chloride salt and graphite was measured. It was shown that the permeability of the compound depends on the bulk density of the compound, as well as the amount of NH3absorbed in the magnesium chloride matrix. Additionally, the permeability of magnesium chloride $(\mathrm{MgCl} 2)$ ammoniate reactive compound is compared with the permeability of the manganese chloride $(\mathrm{MnCl} 2)$ reactive compound reported by other researchers. The two salts have similar reactions with ammonia gas with similar reaction kinetics. Although the graphite contents of the reactive compounds were different, it is shown that the permeabilities of both compounds are within the same order of magnitude. However, it is shown that upon absorbing ammonia, the permeability decrease in magnesium chloride compound was larger than the decrease of permeability in the manganese chloride compound.
\end{abstract}

Keywords: Thermal energy storage; Thermochemical; Porosity; Permeability; Ammonia; Magnesium chloride

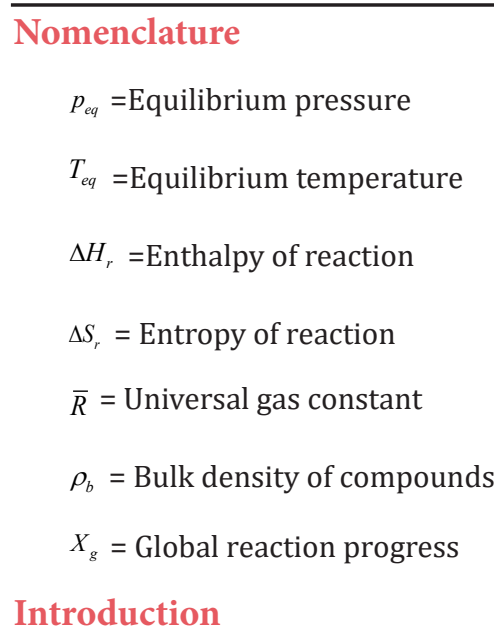

Thermochemical energy storage is an attractive form of energy storage to be used by renewable energy systems. Solar thermal powerplants and industrial waste heat storage systems can particularly benefit from thermochemical energy storage systems due to their high energy storage density and long storage period without major losses of the stored energy. The reaction of magnesium chloride salt and ammonia is particularly a good candidate for thermochemical energy storage applications. Thehigh enthalpy of reaction, $\left(\Delta H_{r}=\frac{55.7 \mathrm{~kJ}}{\text { molNH}_{3}}\right)$ high energy storage density $\left(1.723 \mathrm{MJ} / \mathrm{kg} \mathrm{MgCl}_{2} \cdot 2 \mathrm{NH}_{3}\right.$ or $\left.3.27 \mathrm{MJ} / \mathrm{kg} \mathrm{NH}_{3}\right)$, fast kinetics, sustainability of material harvesting, and cost are among the reasons for utilizing magnesium chloride and ammonia reaction. Further energy recovery can be used for food processing, heating, cooling, and refrigeration.

In studying the performance of solid-gas reactive compounds, it was shown that the thermal conductivity and permeability of the reactive compound play an important role in controlling and advancement of the reaction[1-7]. Similarly, in the reaction of ammonia with the magnesium chloride, the permeability of the salt matrix can be the determining factor for the reaction being constrained by the diffusion of either heat or gas through the reactive compound. The permeability of a reactive compound consisting $80 \% \mathrm{wt} . \mathrm{MgCl}_{2} \cdot 2 \mathrm{NH}_{3}$ and 
20\%wt. Expandable Graphite (EG) at different densities of the compound was measured at the fully absorbed $\left(\mathrm{MgCl}_{2} \cdot 6 \mathrm{NH}_{3}\right)$ and fully desorbed $\left(\mathrm{MgCl}_{2} .2 \mathrm{NH}_{3}\right)$ states and is reported here. It is shown that the permeability of the compound drops as the density of the compound increases. Additionally, absorption of ammonia into magnesium chloride diammoniate salt drops the permeability of the compound further.

\section{Experimental Setup and Procedure}

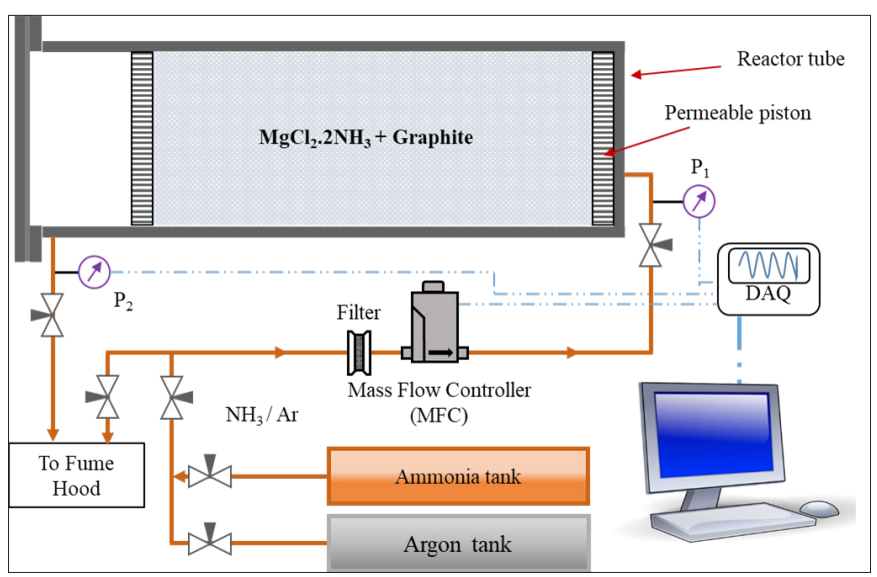

Figure 1: Schematic of the experiment setup.

The permeability of the compound was measured by passing ammonia or argon gas through the reactive compound and measuring the gas flow rate and the pressure difference at both ends of the compound. Figure 1shows a simplified schematic of the experimental setup. The full description of the setup is given by Hedayat[5]. The experimental setup consists of a tube with an internal diameter of $47.5 \mathrm{~mm}$ and a length of $250 \mathrm{~mm}$ made from 316L stainless steel. The tube was filled with salt and graphite complex and two permeable pistons held the complex in place from both ends. During the measurement experiments, the magnesium chloride salt was either in diammoniate (desorbed) or hexammoniate (fully reacted) state to measure the permeability of the compound in the two states of the salt. Since argon gas does not react with the reactive compound, argon was used in measuring the permeability of reactive compound in the desorbed state $\left(\mathrm{MgCl}_{2} \cdot 2 \mathrm{NH}_{3}\right)$. To measure the permeability of reactive compound in fully reacted state $\left(\mathrm{MgCl}_{2} \cdot 6 \mathrm{NH}_{3}\right)$, ammonia gas was used to prevent possible release of ammonia from the compound.

Ammonia and argon gases were supplied from their respective tanks into the supply line which was connected to the Mass Flow Controller (MFC). The MFC controlled and measured the mass flow rate in several steps, going from lower to higher flow rates. In each step, the flow rate was set, and after the flow rate and pressure variations stabilized, the pressures and the flow rate were recorded over one minute. The measurements were averaged for each step to minimize the measurement errors due to random signal noise.

Two different MFCs were used to measure and control the flow of gas. The first MFC was a P9-B model from MKS Instruments with a full-scale flow rate of 3650 SCCM of $\mathrm{NH}_{3}$ (5000SCCM of $\mathrm{N}_{2}$ ). The accuracy of the MKS mass flow controller was reported as 1\% of the set point. Since the flow rate of ammonia from this MFC was not enough for other experiments [8] a second MFC (Hitachi Metals Aera Transformer type FC-PAR7820-C) was used to measure and control the flow rate of the gas into the reactor up to 40000 SCCM of ammonia. The second controller's accuracy was reported by the manufacturer to be $2 \%$ of the full-scale range (800SCCM).

Two AST43001 $\mathrm{F}^{1}$ pressure transducers were installed on both ends of the reactor to measure the pressure drop of the gas during the permeability experiments. The accuracy of the pressure transducers has been reported by the manufacturer as $\pm 0.25 \%$ of full-scale range, which translates to $8.6 \mathrm{kPa}$. However, the transducers were calibrated by measuring the pressure of saturated ammonia vapor at known temperatures, and the accuracy of the measurement was about $1 \mathrm{kPa}$.

The MKS mass flow controller was directly controlled by a web-app provided by the manufacturer onboard of the unit. The pressure transducers and the Aera Transformer MFC were monitored and controlled by a Jabjack U6 data acquisition (DAQ) module. A Labview program was made for this experimental setup to control the flow rate and read the pressure and flow rate signals.

The raw salt used for all the experiments was 99\% pure anhydrous magnesium chloride $\left(\mathrm{MgCl}_{2}\right)$ purchased from Alfa Aesar $2 \mathrm{~F}^{2}$ company, and the graphite was purchased from Asbury Carbons $3 \mathrm{~F}^{3}$. The anhydrous magnesium chloride salt was put into the reactor tube and absorbed ammonia gas to form magnesium chloride hexammoniate $\left(\mathrm{MgCl}_{2} \cdot 6 \mathrm{NH}_{3}\right)$. The reacted salt was then heated to $250{ }^{\circ} \mathrm{C}$ to release ammonia and form magnesium chloride diammoniate slat $\left(\mathrm{MgCl}_{2} \cdot 2 \mathrm{NH}_{3}\right)$. The pure salt, magnesium chloride diammoniate salt (called desorbed salt), or magnesium chloride hexammoniate salt (called absorbed salt) were mixedwith graphite, in a rotating plastic bottle to make a visually homogeneous mixture used for the experiments. The mixture was poured in the reactor using different methods to achieve different compound densities. These methods are fully described by Hedayat[9]. Table 1 lists a description of the six different salt matrices used to measure their permeability in this study.

Density of the compounds $(\rho)$ were measured by measuring the amount of salt and graphite poured into the reactor in each case and measuring the bulk volume of the compound in the reactor. The permeability of the compound was calculated using Equation (1), derived from Darcy's Law and the assumption that the gas behaves as an ideal gas.

\footnotetext{
${ }^{1}$ American Sensor Technologies

${ }^{2}$ www.Alfa.com

${ }^{3}$ www.Asbury.com
} 


$$
k=\frac{2 Q \mu L}{A}\left(\frac{P_{s t d}}{P_{1}^{2}-P_{2}^{2}}\right)
$$

In Equation (1), $\mathrm{Q}$ is the flow rate measured by the MFC (reported in SCCM), A is the cross section area of the reactor, $\mu$ is the dynamic viscosity of the gas, Lis the length of the salt compound, $\mathrm{P}_{\text {std }}$ is the standard pressure $(1 \mathrm{~atm})$, and $\mathrm{P}_{1}$ and $\mathrm{P}_{2}$ are the pressure at the inlet and outlet of the reactor respectively (as shown in Figure 1).

\section{Results and Discussion}

Table 1 lists the measured density and permeability of the reactive compound and Figure 2shows the permeability of the reactive compound in both absorbed and desorbed states as a function of the density of the desorbed compound $\left(\mathrm{MgCl}_{2} \cdot 2 \mathrm{NH}_{3}\right)$. The uncertainty of measurement for each case is calculated based on Equation (1) and the uncertainty of each measuring instrument. Due to the low uncertainty of the density measurements, the horizontal error bars would be too small to show in Figure 2 and therefore they are omitted.

Table 1: Specification of cases and preparation method for the single-cell reactor experiments.

\begin{tabular}{|c|c|c|}
\hline No. & Case & Description \\
\hline 1 & $\begin{array}{c}100 \% \mathrm{MgCl}_{2^{*}} \\
0 \% \text { graphite } \\
0 \% \text { compaction }\end{array}$ & $\begin{array}{l}\text { Pure } \mathrm{MgCl}_{2} \text { salt poured into the reactor, and after expansion of salt } \\
\text { through absorption of ammonia the volume of the reactor is filled without } \\
\text { compressing the salt after. }\end{array}$ \\
\hline 2 & $\begin{array}{l}80 \% \mathrm{MgCl}_{2} \cdot 2 \mathrm{NH}_{3} \\
20 \% \text { graphite } \\
0 \% \text { compaction }\end{array}$ & $\begin{array}{l}\mathrm{MgCl}_{2} \cdot 2 \mathrm{NH}_{3} \text { salt mixed with } 20 \% \text { wt. graphite, poured into the } \\
\text { reactor until it fills the reactor volume. }\end{array}$ \\
\hline 3 & $\begin{array}{l}80 \% \mathrm{MgCl}_{2} \cdot 2 \mathrm{NH}_{3} \\
20 \% \text { graphite } \\
20 \% \text { compaction }\end{array}$ & $\begin{array}{l}\quad \mathrm{MgCl}_{2} \cdot 2 \mathrm{NH}_{3} \text { salt mixed with } 20 \% \text { wt. graphite poured into the } \\
\text { reactor and had pressed to add } 20 \% \text { more mixture than case } 2 \text {. }\end{array}$ \\
\hline 4 & $\begin{array}{l}80 \% \mathrm{MgCl}_{2} \cdot 2 \mathrm{NH}_{3} \\
20 \% \text { graphite } \\
40 \% \text { compaction }\end{array}$ & $\begin{array}{l}\mathrm{MgCl}_{2} \text { salt mixed with graphite, then mixed with DCM, poured into } \\
\text { the reactor until it fills the reactor volume. DCM extracted by evaporation } \\
\text { using vacuum and heat. Then the salt is expanded by the absorption of } \\
\text { ammonia. }\end{array}$ \\
\hline 5 & $\begin{array}{l}80 \% \mathrm{MgCl}_{2} \cdot 2 \mathrm{NH}_{3} \\
20 \% \text { graphite } \\
60 \% \text { compaction }\end{array}$ & $\begin{array}{l}\mathrm{MgCl}_{2} \text { salt mixed with graphite, then mixed with DCM, poured into } \\
\text { the reactor until it fills the reactor volume. DCM extracted by evaporation } \\
\text { using vacuum and heat. Then the salt is expanded by the absorption of } \\
\text { ammonia. }\end{array}$ \\
\hline 6 & $\begin{array}{l}80 \% \mathrm{MgCl}_{2} \cdot 2 \mathrm{NH}_{3} \\
20 \% \text { graphite } \\
80 \% \text { compaction }\end{array}$ & $\begin{array}{l}\mathrm{MgCl}_{2} \text { salt mixed with graphite, then mixed with DCM, poured into } \\
\text { the reactor until it fills the reactor volume. DCM extracted by evaporation } \\
\text { using vacuum and heat. Then the salt is expanded by the absorption of } \\
\text { ammonia. }\end{array}$ \\
\hline
\end{tabular}

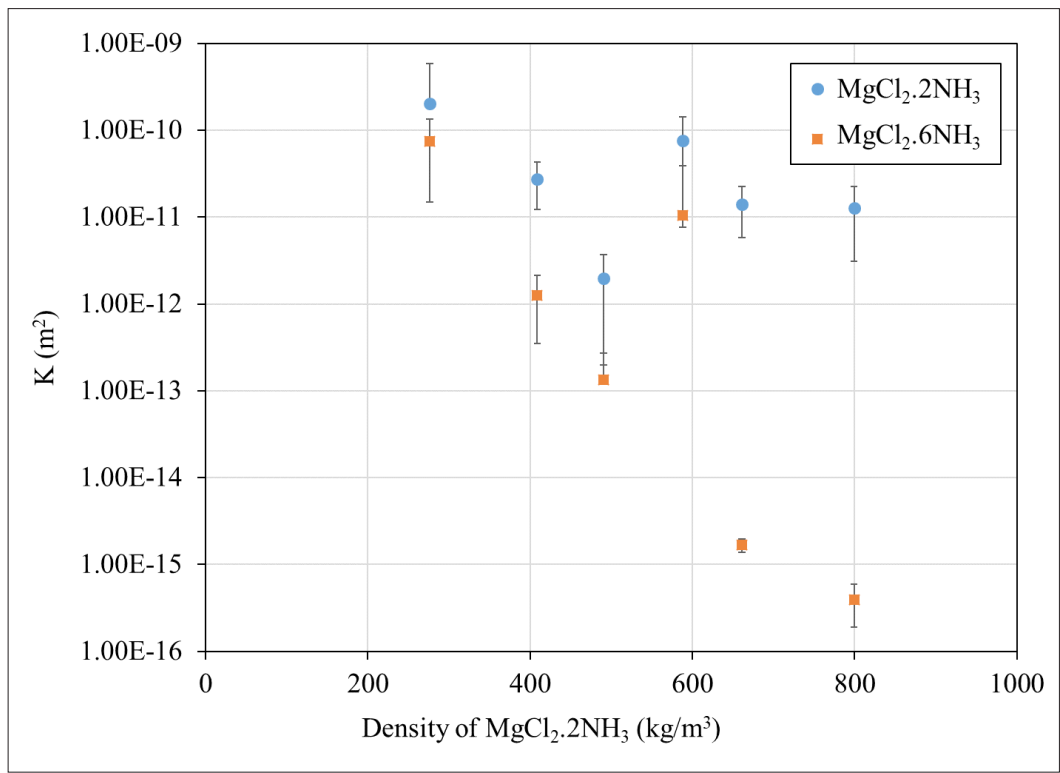

Figure 2: Measured permeability of the reactive compounds. 
Figure 2 shows that for each of the cases, the overall permeability of the compound reduces upon absorption of ammonia into the magnesium chloride salt. This is due to the ammonia gas diffusing into the crystalline structure of the desorbed salt $[10,11]$. Additionally, increasing the density of the compound decreases its porosity $(\varepsilon)$, which decreases the overall permeability of the compound as well. As it was shown by $[1,3,4]$ and Hedayat[9]the reduction of the permeability of the compound below $10^{-15} \mathrm{~m}^{2}$ can have a significant effect on the transport behavior of the ammonia in the reactive compounds(Table 2).

Table 2: Density, porosity, and permeability of the reactive compound for all the cases at both desorbed and saturated states.

\begin{tabular}{|c|c|c|c|c|c|c|c|}
\hline \multicolumn{2}{|r|}{ Case } & \multicolumn{3}{|c|}{$\mathrm{MgCl}_{2} \cdot 2 \mathrm{NH}_{3}$} & \multicolumn{3}{|c|}{$\mathrm{MgCl}_{2} \cdot 6 \mathrm{NH}_{3}$} \\
\hline No. & Description & $\rho\left(\mathrm{kg} / \mathrm{m}^{3}\right)$ & $\varepsilon$ & $\mathbf{K}\left(\mathbf{m}^{2}\right)$ & $\rho\left(\mathrm{kg} / \mathrm{m}^{3}\right)$ & $\varepsilon$ & $\mathbf{K}\left(\mathbf{m}^{2}\right)$ \\
\hline 1 & Pure salt, No graphite & 276.2 & 0.84 & $2.04 \mathrm{E}-10$ & 421.7 & 0.66 & $7.40 \mathrm{E}-11$ \\
\hline 2 & $\begin{array}{l}20 \% \text { graphite, } \\
\text { no compaction. }\end{array}$ & 334.3 & 0.77 & $2.74 \mathrm{E}-11$ & 510.5 & 0.55 & $1.25 \mathrm{E}-12$ \\
\hline 3 & $20 \%$ graphite, $20 \%$ compaction. & 417.4 & 0.71 & $1.96 \mathrm{E}-12$ & 637.5 & 0.44 & $1.34 \mathrm{E}-13$ \\
\hline 4 & $20 \%$ graphite, $40 \%$ compaction. & 588.2 & 0.667 & $7.54 \mathrm{E}-11$ & 835.2 & 0.367 & $1.05 \mathrm{E}-11$ \\
\hline 5 & $20 \%$ graphite, $60 \%$ compaction. & 661 & 0.604 & $1.41 \mathrm{E}-11$ & 938.6 & 0.246 & $1.69 \mathrm{E}-15$ \\
\hline 6 & $20 \%$ graphite, $80 \%$ compaction. & 799.4 & 0.572 & $1.28 \mathrm{E}-11$ & 1135.1 & 0.187 & $3.91 \mathrm{E}-16$ \\
\hline
\end{tabular}

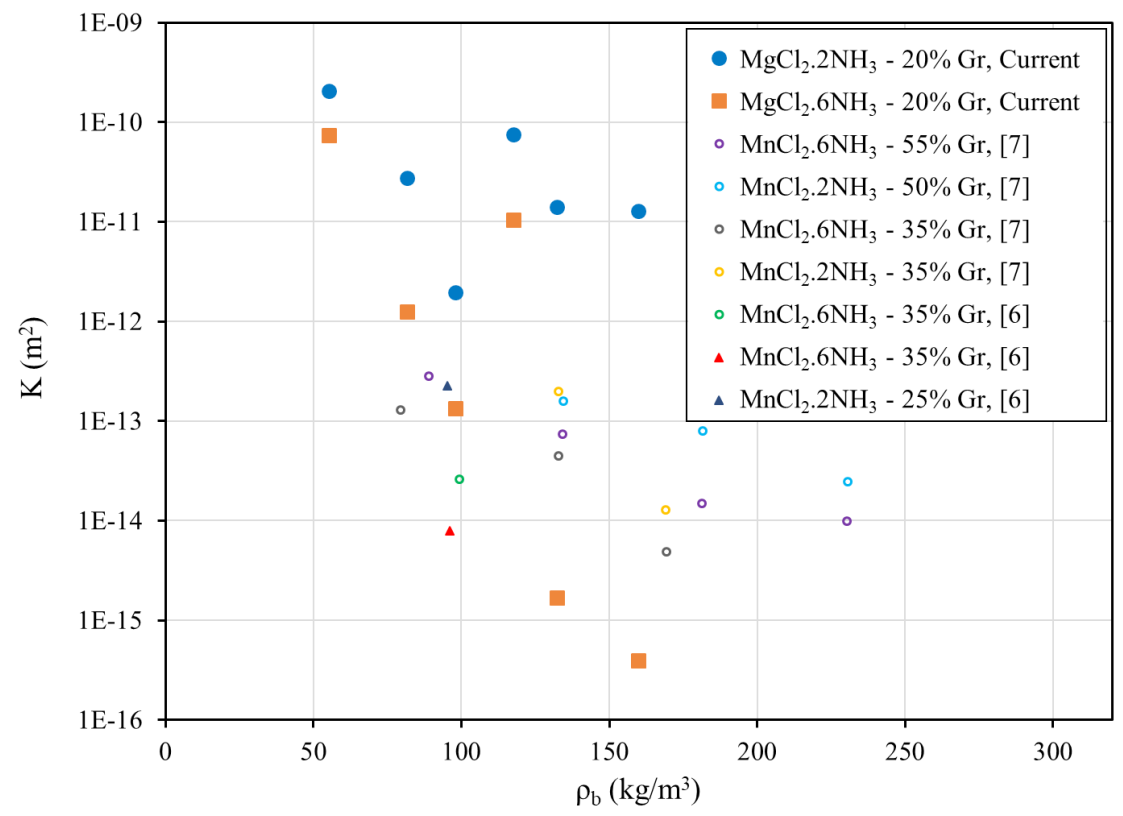

Figure 3: Comparison of permeability measurements with other studies [6,7].

Figure 3 shows a comparison of the measured permeability of magnesium chloride $\left(\mathrm{MgCl}_{2}\right)$ and graphite reactive compounds with the values reported by Han [7]\&L'Haridon[6] for manganese chloride $\left(\mathrm{MnCl}_{2}\right)$ and graphite compounds. Manganese chloride salt reacts with ammonia in a manner similar to magnesium chloride with similar reaction kinetics and can be used in a thermochemical energy storage system as well. The measurements by Han [7]\&L'Haridon[6] were conducted on reactive complexes with more graphite content, and different preparation methods. Comparing the measurements based on the density of the graphite binder shows 
the permeability drop for magnesium chloride $\left(\mathrm{MgCl}_{2}\right)$ complexes is greater than the permeability drops of manganese chloride $\left(\mathrm{MnCl}_{2}\right)$ complex, which could be due to the bigger contribution of the salt grains in the permeability for magnesium chloride reactive compounds in our experiments. It would be beneficial to match the permeability measurements for such compounds with empirical equations for calculation of permeability to determine the importance of salt grain sizes, internal crystalline structure, overall porosity of the compound as it absorbs ammonia.

The large variation in the permeability of the magnesium chloride compound as the reaction goes to completion, coupled with the conclusion that permeability constrains the absorption and heat generation rates $[5,8,9]$, is of concern when a thermochemical energy storage device using this compound is designed. During operation as an absorbent for the $\mathrm{NH}_{3}$ gas the reaction front travels from the cooled surface much as ice grows from a cold surface. When such mass transfer limitations are present, the permeability of the compound in the cooled region drops orders of magnitude, blocking the flow of the gas and reducing the gas absorption and heat generation rates $[5,8,9]$. Conversely, when the device is recharged by heating, the desorbed NH3 vapor will have limited pathways for removal, increasing pressures and equilibrium temperatures, thus reducing heat absorption rates.

\section{Conclusion}

The permeabilities of magnesium chloride and graphite compound at six different densities were measured. It was shown that the permeability of the compound decreases with an increase in the bulk density of the compound, or as the compound absorbs ammonia. The measured permeabilities show a similar magnitude and trend with other reported measurements for a similar compound. However, the permeability of magnesium chloride compounds used in this study show a bigger variation between the desorbed and absorbed states compared to manganese chloride compound with higher graphite content.

\section{References}

1. Lu HB, Mazet N, Spinner B (1996) Modelling of gas-solid reactioncoupling of heat and mass transfer with chemical reaction. Chem Eng Sci 51(15): 3829-3845.

2. Mazet N, Amouroux M, Spinner B (1991) Analysis and experimental study of the transformation of a non-isothermal solid/gas reacting medium. Chem Eng Commun 99(1): 155-174.

3. Lu HB, Mazet N (1999) Mass-transfer parameters in gas-solid reactive media to identify permeability of IMPEX. AIChE J 45(11): 2444-2453.

4. Han JH, Lee KH, Kim DH, Kim H (2000) Transformation analysis of thermochemical reactor based on thermophysical properties of graphite- $\mathrm{MnCl}_{2}$ Complex. Ind Eng Chem Res 39(11): 4127-4139.

5. Hedayat Mofidi SA, Udell KS (2017) Study of heat and mass transfer in $\mathrm{MgCl}_{2} / \mathrm{NH}_{3}$ thermochemical batteries. J Energy Resour Technol 139(3): 032005-032005-10.

6. L'Haridon F, Mauran S (1995) Permeability of a swelling reactive material. CANCAM 95: 422-423.

7. Han JH, Lee KH (2001) Gas permeability of expanded graphite-metallic salt composite. Appl Therm Eng 21(4): 453-463.

8. Hedayat Mofidi SA, Udell KS (2019) Absorption process in $\mathrm{MgCl}_{2}-\mathrm{NH}_{3}$ thermochemical batteries with constant mass flow rate. J Energy Resour Technol 141(6): 062004-062004-10.

9. Hedayat Mofidi SA (2019) Analysis and parametric study of magnesium chloride and ammonia thermochemical energy storage systems and thermal batteries. PhD Dissertation, University of Utah, USA.

10. Hummelshøj JS, Sørensen RZ, Kustova M Yu, Johannessen T, Nørskov JK, et al. (2006) Generation of nanopores during desorption of $\mathrm{NH}_{3}$ from $\operatorname{Mg}\left(\mathrm{NH}_{3}\right) 6 \mathrm{Cl}_{2}$. J Am Chem Soc 128(1): 16-17.

11. Sørensen RZ, Hummelshøj JS, Klerke A, Reves JB, Vegge T, et al. (2008) Indirect, reversible high-density hydrogen storage in compact metal ammine salts. J Am Chem Soc 130(27): 8660-8668. 